\title{
Pulmonary response to agate dust in vivo and cytotoxic and haemolytic effects in vitro
}

\author{
J L KAW AND M WASEEM
}

From the Industrial Toxicology Research Centre, Lucknow 226001, India

ABSTRACT The pulmonary response to agate dust in vivo was investigated and also its cytotoxic action on peritoneal macrophages and sheep erythrocytes in vitro. The results were compared with quartz dust as the known fibrogenic dust and emery dust (Corundum) was used as a control dust. Agate increased the wet and dry weight of lungs and induced increased collagen formation and a non-reversible fibrotic reaction in the lungs. The tissue response and lung changes were of milder intensity than seen in rats exposed to quartz. In vitro, the extent of dye-uptake and haemolysis yielded results similar to those of the in vivo studies. Release of lactic dehydrogenase into the culture medium was similar in both the agate and emery exposed cells but significantly less when compared with quartz treated cells.

The effects of mineral dusts on lungs have been studied experimentally by exposing animals to dusts by inhalation, by the instillation of dust into the lungs intratracheally, and by investigating dust-cell interactions in vitro, using erythrocytes, macrophages, and tissue culture cells lines. ${ }^{1-5}$ Using these test systems it is possible to screen many dusts for their possible effects on the lungs when inhaled and to understand the mechanism of the cytotoxic, fibrogenic, and possibly the carcinogenic actions of some particulate and fibrous environmental and industrial pollutants. ${ }^{6-9}$

Agate is a cryptocrystalline variety of silica that is used as an abrasive in industry. It replaces ballmills, particularly in the manufacture of substances where the product has to be absolutely free of iron contamination. It is also used in manufacturing mortars and pestles and fulcra and bearings of scientific and precision balances. The present studies were aimed at investigating the biological effects of agate dust in vivo and in vitro and to comparing the results with those obtained with the highly fibrogenic dust, quartz, and an inert dust, emery (Corundum).

\section{Materials and methods}

IN VIVO STUDIES

We divided 53 male Wistar strain albino rats (weighing 200-250 g) of the Industrial Toxicology Research Centre animal colony into four groups. The 16 animals in group 1 were inoculated intratracheally with

Received 10 December 1984 Accepted 28 January 1985
$1 \mathrm{ml}$ of sterilised physiological saline containing $50 \mathrm{mg}$ of quartz dust (DQ). The 12 animals in group 2 and the 15 in group 3 were similarly inoculated with agate $\frac{7}{0}$ and emery (Corundum) dusts, respectively. The $10 \stackrel{\Phi}{-}$ animals in group 4 were inoculated with $1 \mathrm{ml}$ of phys- $\vec{\theta}$ iological saline alone. Most of the particles in all the o dusts were less than $5 \mu \mathrm{m}$ in diameter. The anima $\$$ were killed at different intervals up to 180 days whe their lungs were removed and the wet weight dete mined. The lungs were next gently distended with a solution of $10 \%$ formal saline $(\mathrm{v} / \mathrm{v})$ injected through 0 the trachea. The trachea was tied off and put in $10 \% \nsubseteq$ formal saline. After preliminary fixation, blocks of $\overrightarrow{\overrightarrow{0}}$ tissue were selected along the long axis of the lungs 3 and embedded in paraffin. Multiple sections of $5 \mu \mathrm{m}$ thickness were cut and stained with haematoxylin and eosin and silver impregnated for reticulin. The quan- $\bar{O}$ titation of collagen in histopathological study was $\frac{\Phi}{3}$ assessed according to the method of Belt and King. ${ }^{10}$ 음

All the lung tissue except that used for histo- 3 . pathological studies was dried at $105^{\circ} \mathrm{C}$. Tissue shavings and paraffin embedded blocks were added to it and the whole treated thrice with xylene at $37^{\circ} \mathrm{C}$. The 의 mixture was again dried, and when a constant weight had been reached the weight was recorded. This repre- $\frac{7}{0}$ sented the total dry weight of lungs minus the tissue lost in the preparation of the sections. Collagen esti- $\sim$ mation was performed according to the method of $N$ Stegemann. ${ }^{11}$

IN VITRO STUDIES

Cytotoxic studies

The cytotoxic studies were carried out on guinea pig peritoneal macrophages. The method of harvesting ? 
and culture was similar to that described earlier. ${ }^{12}$ Briefly, the cells were obtained from the peritoneal lavage and seeded in $90 \mathrm{~mm}$ sterilised disposable plastic petri dishes. After adherence of the cells, the cells were exposed to different dusts suspended in Eagle's minimum essential medium. Before adding to the cell culture, homologous serum was added to give a concentration of $10 \%$. After 20 hours of dust-cell interaction the lactic dehydrogenase (LDH) activity was estimated in the supernatant and cell monolayers as described earlier. ${ }^{1314}$ In a parallel set of experiments the extent of acid dye uptake by macrophage monolayers exposed to various dusts was assessed. ${ }^{15}$

\section{Haemolytic studies}

Haemolytic studies were carried out on plasma free sheep erythrocytes using the method described earlier. ${ }^{16}$

\section{Results}

Table 1 shows the changes in the wet weight of the lungs from the rats exposed to the various dusts. Those from the animals inoculated with the agate and quartz dusts showed an increase in wet weight by comparison with the lungs from the rats exposed to emery $(\mathrm{p}<0.05$ and $\mathrm{p}<0.01$ respectively). Even though the wet weight of the lungs from animals exposed to quartz was more than those of the lungs from the rats exposed to agate, the results were significant only at 180 days $(\mathrm{p}<0.05)$.

Table 2 shows the changes in the dry weight of lungs. The dry weight of the lungs of rats exposed to agate was more than those of the animals exposed to emery, though the values were statistically significant only at 60 days. The dry weight of the lungs from the animals exposed to quartz was also higher than those of the animals exposed to emery ( $<<0.001$ at 120 days and $\mathrm{p}<0.05$ at 180 days). No statistically significant difference was observed in the dry weight of the lungs from the rats exposed to agate or quartz despite the fact that the values were higher in the animals exposed to quartz at all times.

Table 1 Changes in the wet weight of lungs $(g)$ at different intervals after exposure to agate dust. Figures in parentheses represent the number of animals used

\begin{tabular}{llllc}
\hline $\begin{array}{l}\text { Days after } \\
\text { exposure }\end{array}$ & Agate & Emery & Quartz & Control \\
\hline 60 & $4.33(3)$ & $2.91(5)$ & $7.46(3)$ & $2.92(3)$ \\
& \pm 0.56 & \pm 0.48 & \pm 1.96 & \pm 0.18 \\
120 & $5.64(3)$ & $2.96(3)$ & $7.46(3)$ & $2.99(3)$ \\
& \pm 1.02 & \pm 0.34 & \pm 0.74 & \pm 0.24 \\
180 & $5.51(3)$ & $3.15(7)$ & $8.35(2)$ & $2.91(3)$ \\
& \pm 1.62 & \pm 0.52 & \pm 0.22 & \pm 0.24 \\
\hline
\end{tabular}

$\pm \mathrm{SD}$.
Table 2 Changes in the dry weight of lungs $(\mathrm{g})$ at different intervals after exposure to agate dust. Figures in parentheses represent the number of animals used

\begin{tabular}{lcccc}
\hline $\begin{array}{l}\text { Days after } \\
\text { exposure }\end{array}$ & Agate & Emery & Quartz & Control \\
\hline 60 & $0.92(3)$ & $0.45(5)$ & $1.21(3)$ & $0.50(3)$ \\
& \pm 0.34 & \pm 0.10 & \pm 0.49 & \pm 0.07 \\
120 & $1.02(3)$ & $0.54(3)$ & $1.58(3)$ & $0.48(3)$ \\
& \pm 0.37 & \pm 0.21 & \pm 0.18 & \pm 0.06 \\
180 & $1.20(3)$ & $0.61(7)$ & $2.35(2)$ & $0.52(3)$ \\
& \pm 0.35 & \pm 0.11 & \pm 0.93 & \pm 0.07 \\
\hline
\end{tabular}

$\pm \mathrm{SD}$.

Two months after the inoculation of agate dust, the pulmonary tissue showed development of dust cell granulomas. The skeleton of these lesions was made up of reticulin fibres admixed with a few collagen fibres (fig 1). The alveoli and alveolar ducts surrounding the lesions were emphysematous. In those areas of the lungs with a meagre dust reaction there was an aggregation of free macrophage, most of which contained phagocytosed dust particles. In the animals exposed to quartz the development of silicotic lesions was extensive and there was a greater formation of collagen than in the animals exposed to agate. In animals inoculated with emery the dust was found predominantly within the cytoplasm of macrophages whose morphological details seemed to have been obscured by the phagocytosed dust which occupied the greater part of the cell cytoplasm. There was no evidence of fibrosis.

After four months, the lesions in the animals exposed to agate dust were more developed. The lesions were composed predominantly of macrophages, lymphocytes, and fibroblasts (fig 2). There was a decrease in the number of areas showing free cells in the alveolar lumen and the stroma of the lesions contained a greater number of collagen fibres. On the other hand, the formation of collagen fibres in the quartz induced lesions was extensive. In the animals exposed to emery the pulmonary reaction was similar to that seen at the earlier period.

Six months after the inoculation of agate dust the formation of collagen was similar to that seen at the four month interval (fig 3). The lesions in the animals exposed to agate after six months were less fibrous than those seen in animals exposed to quartz at four months. The development of silicotic lesions in the rats exposed to quartz was more extensive than at four months. The lesions were less cellular but highly collagenous and several fibrotic nodules had coalesced (fig 4). In the animals exposed to emery the dust continued to be localised within the cytoplasm of the macrophages, which tended to aggregate at certain locations without bringing about a proliferation of stromal elements (fig 5).

Biochemically, the collagen increase was maximum 


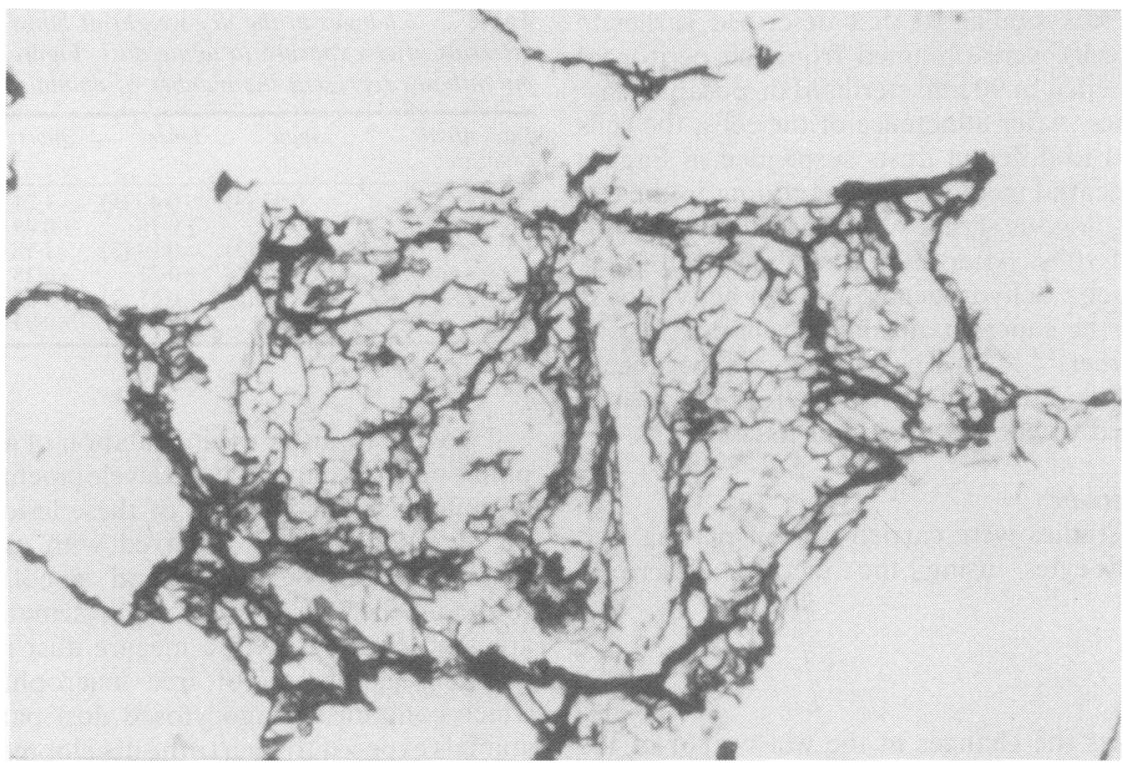

Fig 1 Section of rat lung 60 days after intratracheal inoculation of agate dust, showing pulmonary lesions composed mostly of reticulin fibres and a few collagen fibres. (Silver impregnation $\times 600$.)

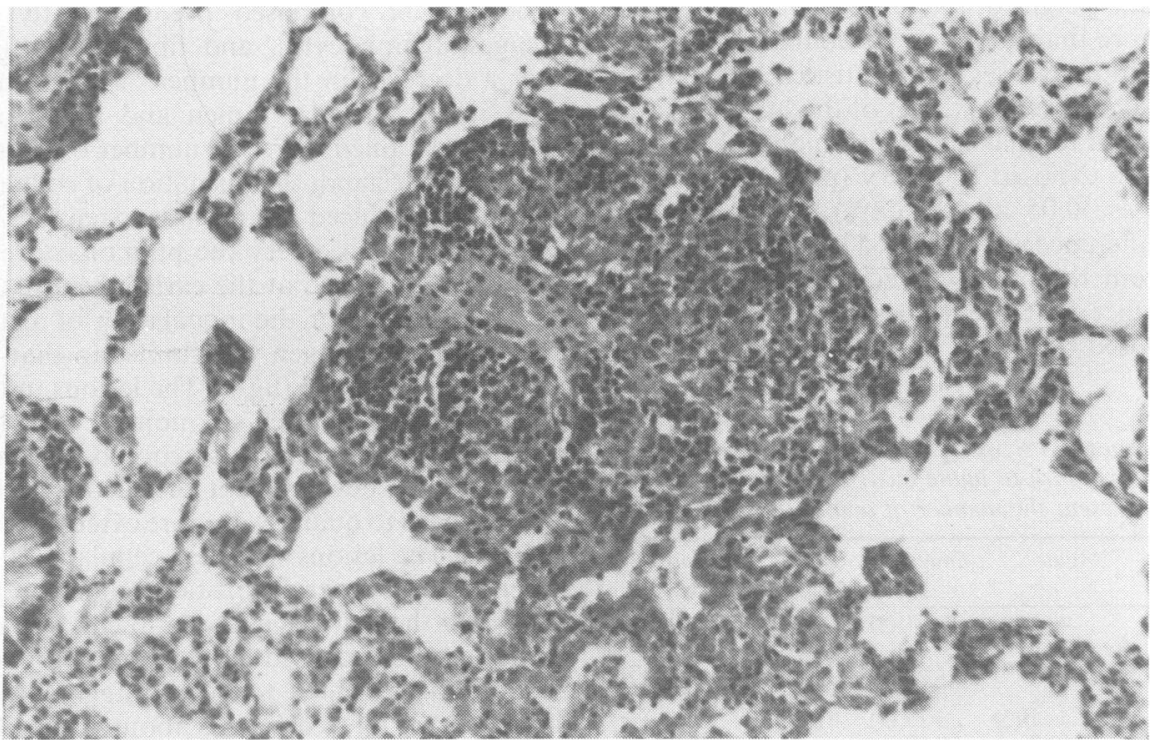

Fig 2 Section of rat lung 120 days after intratracheal inoculation of agate dust, showing high cellularity of nodules. (Haematoxylin and eosin $\times 150$.) 


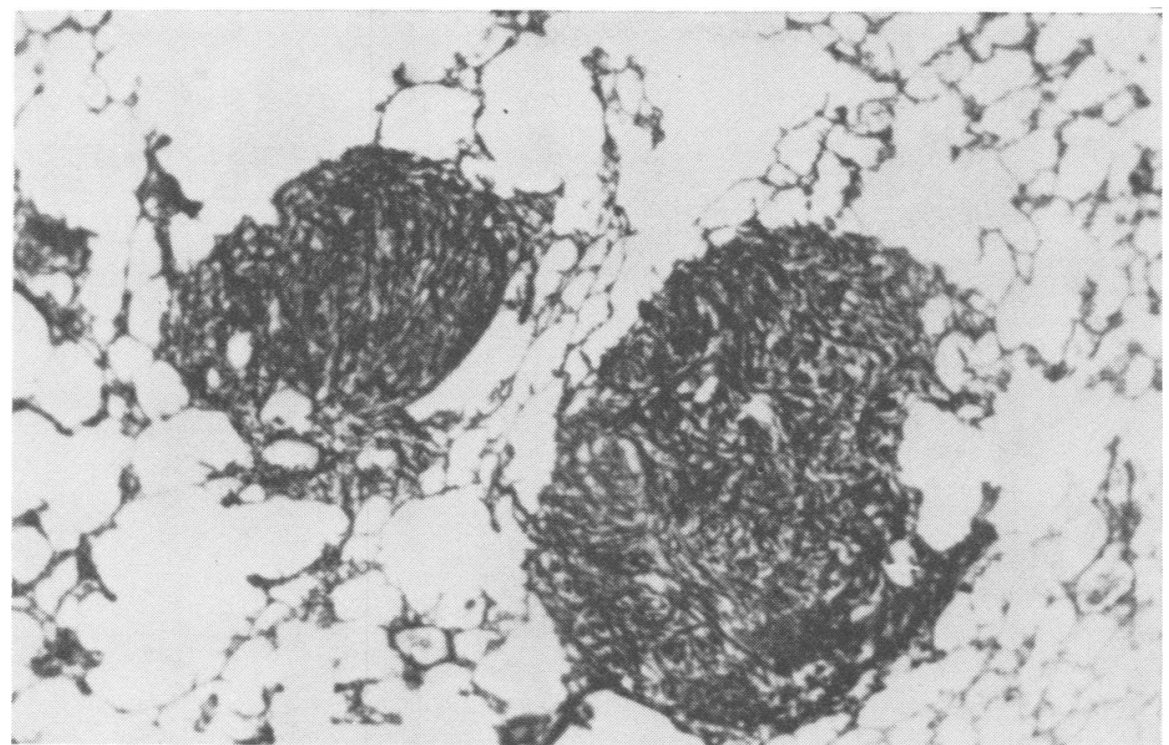

Fig 3 Section of rat lung 180 days after intratracheal inoculation of agate dust showing a progressive increase in number of collagen fibres. (Silver impregnation $\times 60$.)

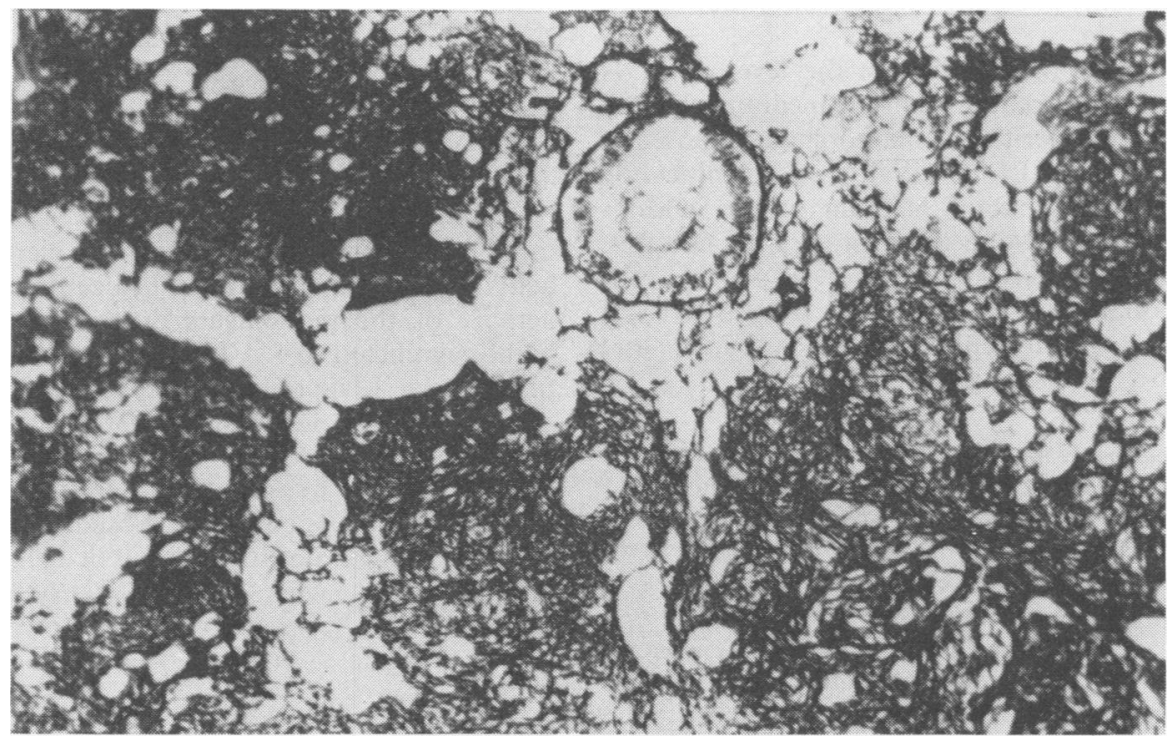

Fig 4 Section of rat lung 180 days after intratracheal inoculation of quartz dust showing highly collagenous and confluent silicotic nodules. (Silver impregnation $\times 60$.) 


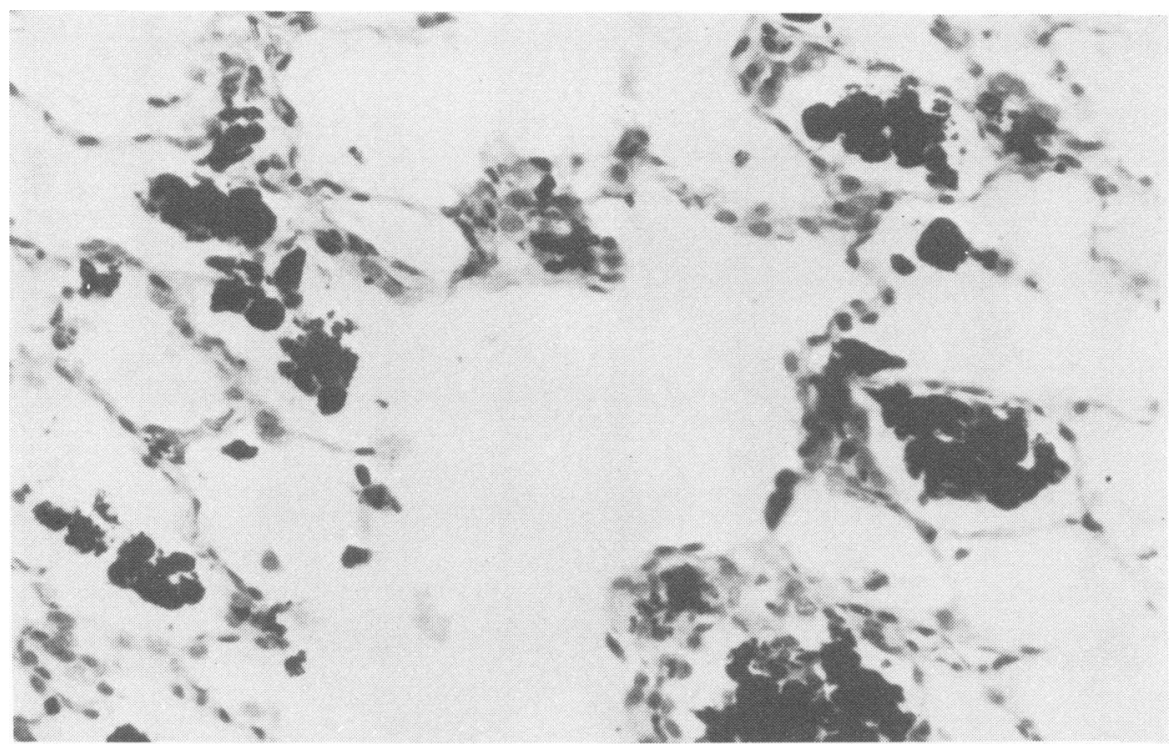

Fig 5 Section of rat lung 180 days after intratracheal inoculation of emery dust showing intra-alveolar localisation of dust without any cellular or stromal reaction. (Haematoxylin and eosin $\times 300$.)

in the animals exposed to quartz and increased with time (table 3). The lung collagen content was observed to be greater in the animals exposed to agate and quartz than in those exposed to emery. Statistically, the values were significant at all periods in the case of quartz ( $\mathrm{p}<0.02$ at 60 and 120 days and $\mathrm{p}<0.05$ at 180 days) but only at 60 days in the case of the animals exposed to agate.

Table 4 shows the changes in the level of LDH activity in the supernatant culture medium and cell monolayers of the peritoneal macrophages exposed to various dusts. The LDH activity was significantly higher in the supernatant medium of the cultures exposed to dusts. Among the dust exposed cultures, the maximum increase was observed in the cells exposed to quartz ( $p<0.0001)$. The LDH activity of the supernatants of the cultures exposed to agate and

Table 3 Changes in the total collagen of lungs ( $m g$ ) at different intervals after exposure to agate dust. Figures in parentheses represent the number of animals used

\begin{tabular}{lllll}
\hline $\begin{array}{l}\text { Days after } \\
\text { exposure }\end{array}$ & Agate & Emery & Quartz & Control \\
\hline 60 & $50.63(3)$ & $24.08(5)$ & $85.03(3)$ & $24.39(3)$ \\
& \pm 23.49 & \pm 05.63 & \pm 48.67 & \pm 02.79 \\
120 & $79.73(3)$ & $38.66(3)$ & $112.95(3)$ & $28.36(3)$ \\
& \pm 35.10 & \pm 16.20 & \pm 21.05 & \pm 02.16 \\
180 & $72.82(3)$ & $38.98(7)$ & $204.89(2)$ & $32.14(3)$ \\
& \pm 21.04 & \pm 05.22 & \pm 100.32 & \pm 03.56 \\
\hline
\end{tabular}

$\pm \mathrm{SD}$.
Table 4 Lactate dehydrogenase activity $(m U)$ of cell cultures exposed to agate dust. Figures in parentheses represent number of observations

\begin{tabular}{lll}
\hline & Supernatant & Monolayer \\
\hline Control cells & $24 \cdot 10 \pm 0.00(2)$ & $91 \cdot 11 \pm 11 \cdot 27(3)$ \\
Cells + quartz & $74.36 \pm 2.84(3)$ & $44.21 \pm 06.96(3)$ \\
Cells + agate & $41 \cdot 53 \pm 6.14(3)$ & $75.03 \pm 11.60(3)$ \\
Cells + emery & $40.19 \pm 6.96(3)$ & $75.03 \pm 04.64(3)$ \\
\hline
\end{tabular}

\pm SD. $\mathrm{mU}=$ milliUnits.

emery were also increased by comparison with the control cell supernatants $(p<0.02$ and 0.05 respectively). The decrease in the level of $\mathrm{LDH}$ in the monolayers parallelled the respective increase in LDH activity in the supernatants. The decrease in the LDH activity of the monolayers exposed to quartz was highly significant $(\mathrm{p}<0.001)$. The total LDH activity (monolayer + supernatant) remained unaltered.

Acid dye uptake was maximum in the cultures 윽 exposed to quartz dust $(p<0.01)$, moderate in the cell cultures exposed to agate $(p<0.01)$, and statistically insignificant in the cultures exposed to emery (fig 6).

Figure 7 illustrates the haemolytic behaviour of the $ᄋ$ different dusts when added to erythrocyte sus- N pensions. The haemolytic effect followed the trend quartz $>$ agate $>$ emery.

\section{Discussion}

The results of the present study show that agate dust 


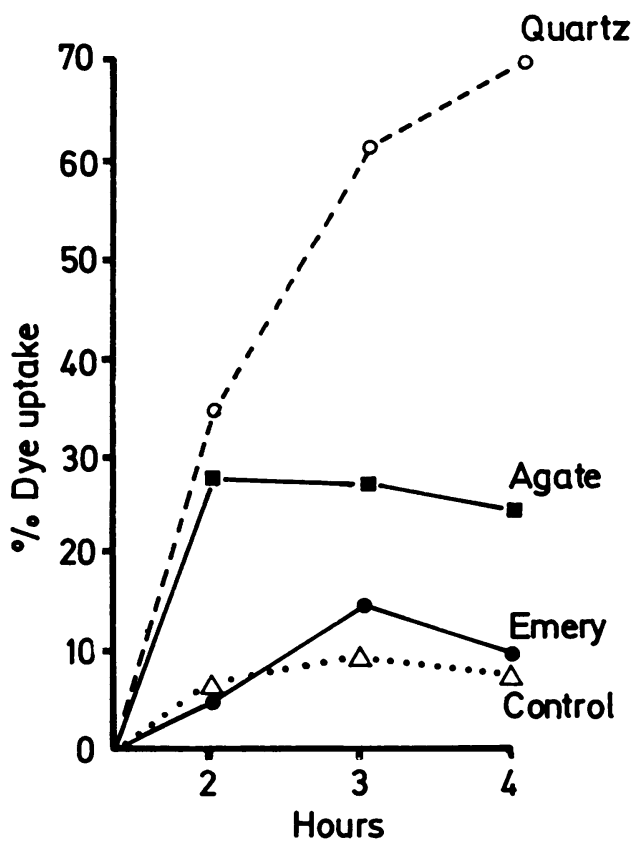

Fig 6 Extent of acid dye uptake by macrophage monolayers exposed to different dusts.

is readily phagocytosed by pulmonary macrophages and that this is followed by the destruction of the alveolar architecture and the replacement of the cellular elements of the dust induced granulomas by lesions composed firstly of reticulin and later of collagen fibres. There was no evidence of regression or reversibility of the lesions. Such characteristic pulmonary changes have been suggested to be paihognomonic of proliferative dusts. ${ }^{17}$ The changes brought about by agate dust were qualitatively similar to those brought about by quartz dust. Nevertheless, the lung weights (both dry and wet) and the collagen content were significantly less in the case of agate dust.

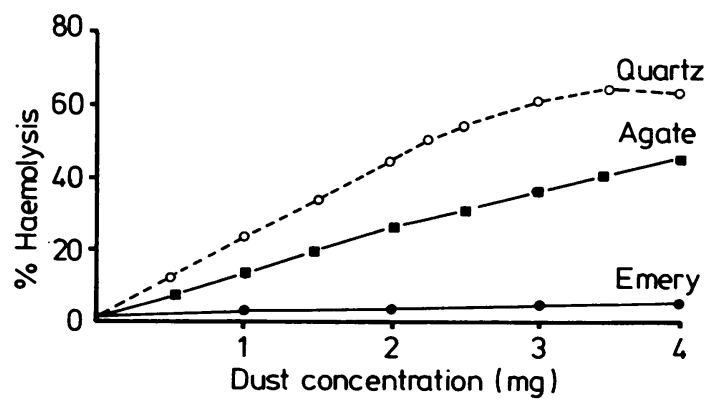

Fig 7 Comparative haemolytic activity of different dusts.
Phagocytosis of cytotoxic dust is associated with a release of significant amounts of LDH both in vivo and in vitro. ${ }^{18-21}$ Release of lactate dehydrogenase into the medium of cultured macrophages, due to increased permeability, is regarded as a sign of damage to the plasma membrane. ${ }^{22}$ Maximum increased levels of this enzyme were observed in the supernatant culture medium of the cells exposed to quartz.

Agate and emery dusts increased the levels of LDH in the culture medium, compared with the control cells, but this increase was significantly less than observed in the cells exposed to quartz. The release of LDH in the cultures exposed to agate and emery could have been due to an increased membrane activity associated with the process of phagocytosis of particulate materials and an identical action on the part of macrophage membranes. The increased LDH activity in the cultures exposed to emery needs special mention, since all the dusts that are believed to be inert have some degree of residual toxicity in one or other test system. Similar observations were made by one of us earlier using mouse macrophages. ${ }^{23}$ Whether the cells showing leakage of cytosolic enzymes could be regarded as dead is a matter of conjecture.

The dye-exclusion and haemolytic studies clearly differentiated between the in vitro reactions observed with agate and emery. The results of these studies were identical to the in vivo studies and lend support to the hypothesis that dust toxicity in vitro can predict with reasonable accuracy the in vivo reactivity of dusts.

We thank $\mathrm{Mr}$ Pratap Singh for preparing thehistological sections and Mr A K Khanna, Mr SK Shukla, Mr Ram Prasad, and Mr Umesh Prasad for technical help.

\section{References}

${ }^{1}$ Macnab G, Harington JS. Hemolytic activity of asbestos and other mineral dusts. Nature 1967;14:807-9.

${ }^{2}$ Styles JA, Wilson J. Comparison between in vitro toxicity of polymer and mineral dusts, and their fibrogenicity. Ann Occup $\mathrm{Hyg}$ 1973;16:241-50.

${ }^{3}$ Harington JS, Allison AC, Badami DV. Mineral fibres: chemical physiochemical and biological properties. Adv Pharmacol Chemother 1974;12:291-409.

${ }^{4}$ Chamberlain M, Brown RC, Davies R, Griffiths DM. In vitro prediction of the pathogenicity of mineral dusts. Br J Exp Pathol 1979:60:320-7.

${ }^{5}$ Smith TJ, Beck BD, Brain JD. Hinds WC, Baron SG, Weil L. Prediction of pneumoconiosis risk by bioassays of particulates from occupational exposures. Ann Occup $\mathrm{Hyg}$ 1982;26:435-48.

${ }^{6}$ Heppleston AG. Silica and asbestos. Contrasts in tissue response. Ann NY Acad Sci 1979;330:725-44.

${ }^{7}$ Mossman BT, Craighead JE. Mechanisms of asbestos carcinogenesis. Environ Res 1981;25:269-80.

${ }^{8}$ Bateman ED, Emerson RJ, Cole PJ. A study of macrophage mediated initiation of fibrosis by asbestos and silica using diffusion chamber technique. Br J Exp Pathol 1982;63:414-25. 
${ }^{9}$ Alto M, Heppleston AG. Fibrogenesis by mineral fibres: an in vitro study of the role of macrophage and fibre length. Br J Exp Pathol 1984;65:91-9.

${ }^{10}$ Belt TH, King EJ. Chronic pulmonary disease in south Wales coalminers III. Experimental studies. D. Tissue reactions produced experimentally by selected dusts from south Wales coalmines. Special Report Series, Medical Research Council (London), 1945;250:29-68.

${ }^{11}$ Stegemann H. Microdetermination of hydroxyproline with chloramine-T and p-dimethylaminobenzaldehyde. Zeitschrift für Physikalische Chemie 1958;311:41-5.

${ }^{12} \mathrm{Kaw}$ JL, Beck EG, Bruch J. Studies of quartz cytotoxicity on peritoneal macrophages of guinea pigs pre-treated with polyvinylpyridine N-oxide. Environ Res 1975;9:313-20.

${ }^{13}$ Kornberg A. Lactic dehydrogenase of muscle. In: Colowick SP, Kaplan NO, eds. Methods of enzymology. Vol 1. New York: Academic Press Inc, 1955:441-3.

${ }^{14}$ Waseem M, Bansal SK, Gupta GSD, Kaw JL. Cytotoxic and hemolytic action of coal-quartz mixtures. Arch Environ Health 1982;37:352-7.

${ }^{15}$ Munch R, Beck EG, Manojlovic N. Untersuchungen über die Reaktion in vitro gezüchteter Zellen nach Kurzzeitiger Inkubation mit $\mathrm{SiO}_{2}$-Staub. Beitr Silikoseforsch 1971;23:175-205.
${ }^{16}$ Kaw JL, Gupta GSD, Narang S, Zaidi SH. Hemolytic activity of $\overline{\bar{\partial}}$ mica dust and its relation to polyvinyl-pyridine N-oxide. $\operatorname{Exp}$ Pathol 1973;8:349-53.

${ }^{17}$ Gross P, Nau CA. Lignite and the derived steam activated carbon-the pulmonary response to their dusts. Arch Environ Health 1967;14:450-60.

${ }^{18}$ Nash T, Allison AC, Harington JS. Physico-chemical properties of silica in relation to its toxicity. Nature 1970;210:259-61.

${ }^{19}$ Beck EG. Die reaktion in vitro gezüchteter Zellen auf partikolförmige Luftverreinigung und hoch polymere Stoffe Forschungsbericht (NRW No 2083). Köln Opladen: West Deutscher Verlag, 1970.

${ }^{20}$ Henderson RF, Damon EG, Henderson TR. Early damage indicators in the lung. I Lactate dehydrogenase activity in the airways. Toxicol Appl Pharmacol 1978;44:291-7.

${ }^{21}$ Emerson RJ, Davis GS. Effect of alveolar lining material coated silica on rat alveolar macrophages. Environ Health Prosp 1983;51:81-4.

${ }^{22} \mathrm{Kaw} \mathrm{JL}$. Tissue culture in pneumoconiosis. CRC Crit Rev Toxicol 1977;5:103-14.

${ }^{23} \mathrm{Kaw}$ JL. Cytotoxic action of quartz dust on stimulated and nonstimulated peritoneal macrophages in vitro. Exp Mol Pathol 1983;38:109-16.

\section{Destruction of manuscripts}

From 1 July 1985 articles submitted for publication will not be returned. Authors whose papers are rejected will be advised of the decision and the manuscripts will be kept under security for three months to deal with any inquiries and then destroyed. 